\title{
Study of Poly(L-aspartic acid). I. Laser Raman Spectrometry
}

\author{
P. Lagant,${ }^{*}$ G. Vergoten, ${ }^{* *}$ C. Loucheux,${ }^{*}$ and G. Fleury*** \\ * Laboratoire de Chimie Macromoléculaire, \\ B. P. 3659650 VILLENEUVE D'ASCQ FRANCE. \\ ** Laboratoire de Physique, Faculté de Pharmacie, \\ rue du Professeur Laguesse 59045 LILLE CEDEX. \\ ***Centre de Technologie Biomédicale I.N.S.E.R.M. \\ 13-17, rue Camille Guérin 59000 LILLE FRANCE.
}

(Received December 20, 1977)

\begin{abstract}
The conformational properties of poly( $\alpha$-L-aspartic acid) (L-Asp) ${ }_{n}$ have been investigated in water, in deuterium oxide and also in the solid state, by Raman scattering. The conformational transition induced by changing the $\mathrm{pH}$ of the solutions has been given special attention. The spectra exhibit a mixture of different conformations. Random-coil and $\beta$-antiparallel pleated-sheet conformations exist in both acidic and ionized forms of the polyacid. In addition a local $\beta_{1}$ helical conformation has been detected in the ionized form. The $\alpha$ helical conformation appeared as the acidic form only.
\end{abstract}

KEY WORDS Poly $(\alpha$-L-aspartic acid $) /$ Raman Scattering / Conformational Transition/

Only a few studies have been carried out up till now on (L-Asp) ${ }_{n}{ }^{1-3}$ Patrone and Conio ${ }^{4}$ showed that only $20 \%$ of the $\alpha$ helical structure exists in $\mathrm{H}_{2} \mathrm{O}$-methanol solutions.

A complete study of the structure of (L-Asp) ${ }_{n}$ has been carried out using infrared, X-rays, circular dichroism, NMR and Raman techniques. ${ }^{5}$ The aim of this paper is to present the results of the laser Raman investigations and discuss them, making reference especially to the results of Koenig and Frushour on (L-Glu) ${ }_{n}{ }^{6}$ and $\mathrm{Yu}$, et al., on (L-Lys) ${ }_{n}{ }^{7}$

\section{EXPERIMENTAL}

( $\beta$-Benzyl L-aspartate $)_{n}$ was synthesised by the $N$ carboxyanhydride method and then debenzylated with dry $\mathrm{HBr}$ in benzyl alcohol. The molecular weight of this sample was about 7,000 and determinated by tonometric measurement (solvent, DMF; refbenzil $\left.M_{w}, 210\right)$. The total debenzylation was controlled by UV spectroscopy $(\lambda, 260 \mathrm{~nm} ; \varepsilon$, $200 / \mathrm{mol}^{-1} \mathrm{~cm}^{-1}$ ) and residual benzyl groups were less than $1 \%$. Debenzylation was also controlled by Infrared spectroscopy and no characteristic band due to the presence of an $\alpha-\beta$ copolypeptide was recorded. Kowacs, et al., ${ }^{16}$ have recorded the IR

\footnotetext{
† To whom all correspondence should be addressed.
}

spectrum of an $\alpha-\beta$ copolypeptide of (L-Asp) ${ }_{n}$. No such bands were present in our spectra or if present, they were too small to be detected.

Generally, an $\alpha \rightarrow \beta$ shift occurs when the debenzylation takes place in a solvent such as DMSO or $\mathrm{DMF}$ and gives rise to the formation of succinimide rings and the appearance of two negative dichroic bands at 258 and $242 \mathrm{~nm}$. Debenzylation of (L-Asp) was performed in $\mathrm{CHCl}_{3}$ by $\mathrm{HBr}$ and no such bands appeared in our spectrum. Another (L-Asp) ${ }_{n}$ sample was obtained from Sigma (molecular weight $\left.M_{w}=14,000\right)$. A small difference between these two materials was detected in their circular dichroism spectra. Raman spectra were recorded using a CODERG T 800 triple monochromator. The 514.5 $\mathrm{nm}$ line of a Spectraphysics Argon ion laser was used as the exciting source, with $400-600-\mathrm{mW}$ power at the sample. The spectra were obtained at a constant temperature of $25^{\circ} \mathrm{C}$.

In order to avoid fluorescence phenomena, the solutions and solids investigated were maintained one week on charcoal then the solutions were dialysed and lyophilized in $\mathrm{H}_{2} \mathrm{O}$ (or $\mathrm{D}_{2} \mathrm{O}$ ). The solids were maintained in the laser beam several hours before recording. The solutions were prepared $24 \mathrm{~h}$ before use. They were compartively less fluorescent than the solids. 
P. Lagant, G. Vergoten, C. LoucheuX, and G. Fleury

Table I. Frequencies $\left(\mathrm{cm}^{-1}\right)$ and assignments of Raman bands for (L-Asp) ${ }_{n}{ }^{a}$

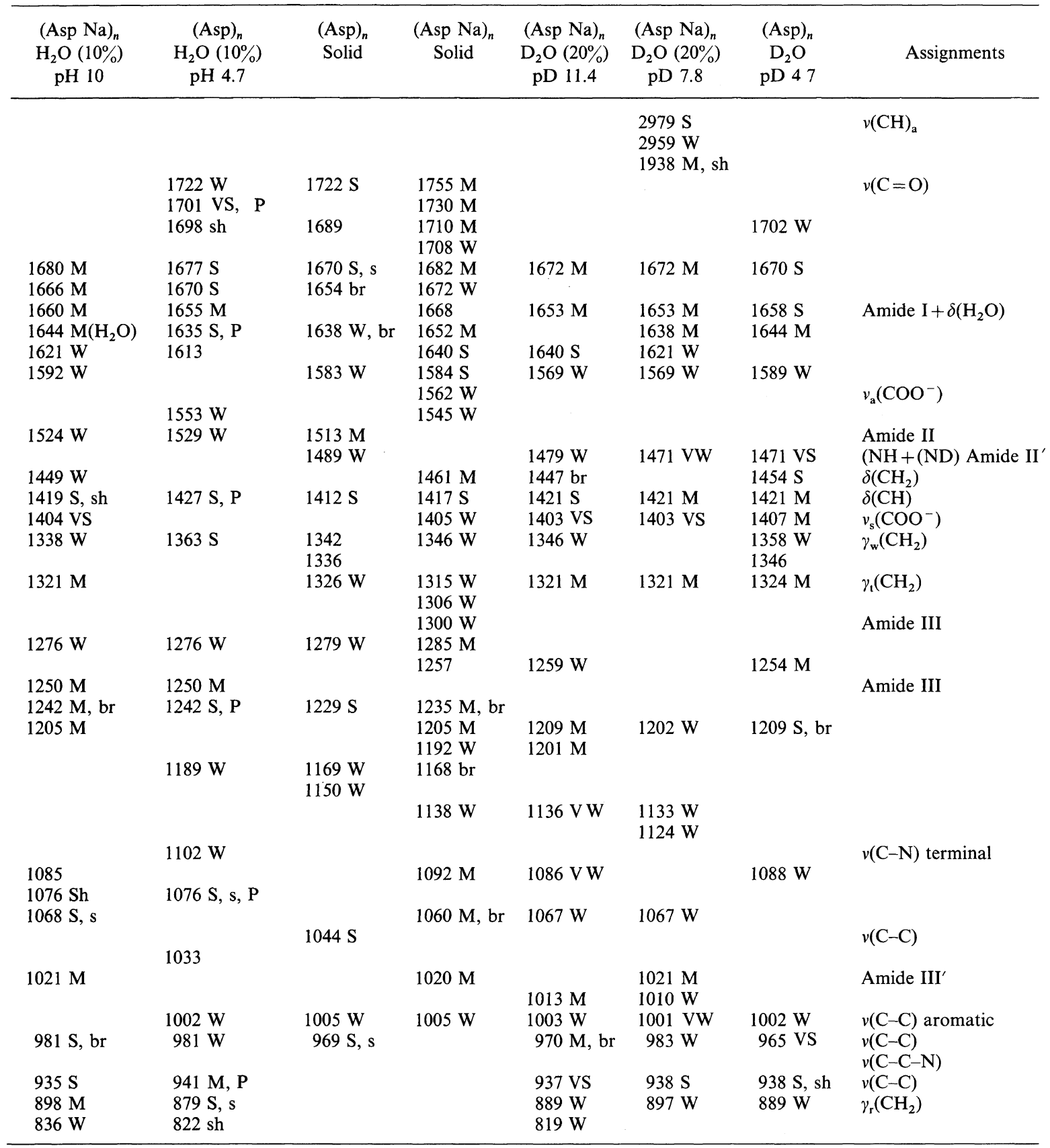

a VS, very strong; S, strong; M, medium; W, weak; VW, very weak; s, sharp; br, broad; sh, shoulder; L, large; $\delta$, deformation mode; $\gamma_{t}$, twisting mode; $\gamma_{\mathrm{w}}$, wagging mode; $\gamma_{\mathrm{r}}$, rocking mode; $v_{\mathrm{s}}$, symmetrical stretching mode; $v_{\mathrm{a}}$, antisymmetrical model; $P$, polarized band. 


\section{RESULTS AND DISCUSSION}

Solid Acid Form (L-Asp)

In Table I, the frequencies of the Raman bands observed for poly(aspartic acid) in the solid state are reported along with the Raman bands of solutions in $\mathrm{H}_{2} \mathrm{O}$ and $\mathrm{D}_{2} \mathrm{O}$.

The amide I band appears in three lines at 1670 , 1654 , and $1638 \mathrm{~cm}^{-1}$ (Figure 1). The first is assignable to a $\beta$ antiparallel structure as reported for (LLys) $)_{n}{ }^{7}$ The second corresponds to the random coil conformation observed by Koenig and Frushour at
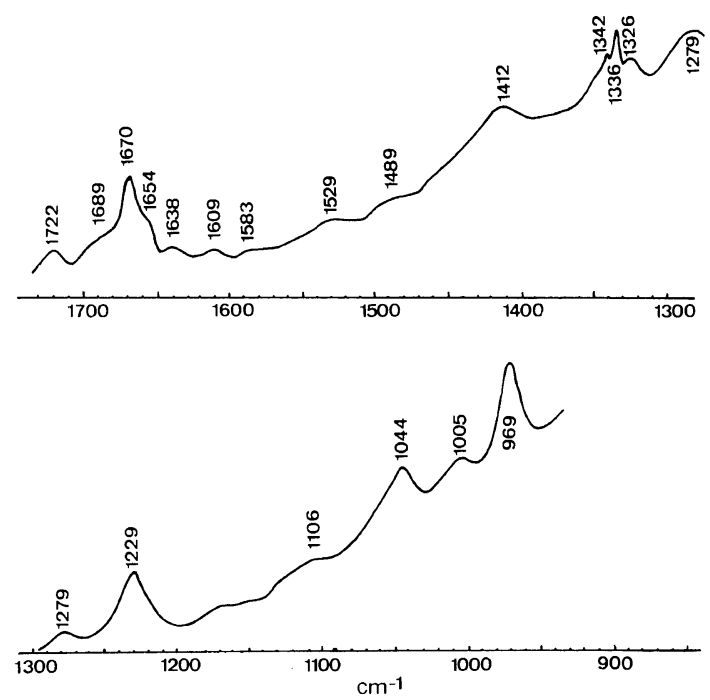

Figure 1. Raman spectra of neutral (L-Asp) ${ }_{n}$ in the solid state.
$1656 \mathrm{~cm}^{-1}$ for (L-Glu) ${ }_{n}{ }^{6}$ The last one is due to the helical conformation $\left(1650 \mathrm{~cm}^{-1}\right.$ in IR).

The band at $1689 \mathrm{~cm}^{-1}$ indicates the $v_{\mathrm{C}=\mathrm{o}}$ stretching of non hydrated $\mathrm{C}=\mathrm{O}$ groups. The one at $1722 \mathrm{~cm}^{-1}$ is due to the $v_{\mathrm{C}=\mathrm{O}}$ stretching of neutral carboxylic groups. However a small number of ionized carboxylic groups is shown to exist, by the presence of a band at $1583 \mathrm{~cm}^{-1}$. Moreover, the small bands at 1609 , and $1005-1002 \mathrm{~cm}^{-1}$ may be assigned to the residual benzyl rings ${ }^{10}$ (less than $1 \%$ as determined by UV spectrometry) (Figure 1).

The sharp and intense amide III band is found at $1229 \mathrm{~cm}^{-1} \quad\left(1270 \mathrm{~cm}^{-1}\right.$ for $(\mathrm{L}-\mathrm{AspNa})_{n}$ and $1230 \mathrm{~cm}^{-1}$ for (L-Asp) ${ }_{n}$ in IR in the solid state), and we have assigned it to the amide III vibrations of antiparallel sheets. A weak band was observed at $1279 \mathrm{~cm}^{-1}$, is discussed in the following paragraph.

Solid Ionized Form ( L-Asp Na) ${ }_{n}$

The spectra of (L-Asp Na) ${ }_{n}$ were difficult to obtain due to intense fluorescence (Figure 2). The analysis of the bands could be made for ( $\mathrm{L}-\mathrm{Asp})_{n}$. The amide I bands at $1672-1668 \mathrm{~cm}^{-1}$ were assigned to a $\beta$ antiparallel conformation (1690-1672 $\mathrm{cm}^{-1}$ in IR). The band at $1652 \mathrm{~cm}^{-1}$ corresponds to the random coil conformation as observed at $1649 \mathrm{~cm}^{-1}$ for $(\mathrm{L}-$ Glu Na) ${ }_{n}$ by Koenig and Frushour. ${ }^{6}$ The band at $1638 \mathrm{~cm}^{-1}$ of the $\alpha$ helix conformation was not present here but a strong band at $1640 \mathrm{~cm}^{-1}$ was observed. It is surprising that such a band occurs at this frequency and we have not be able to identify it.

A band at $1682 \mathrm{~cm}^{-1}$ corresponds to the stretching
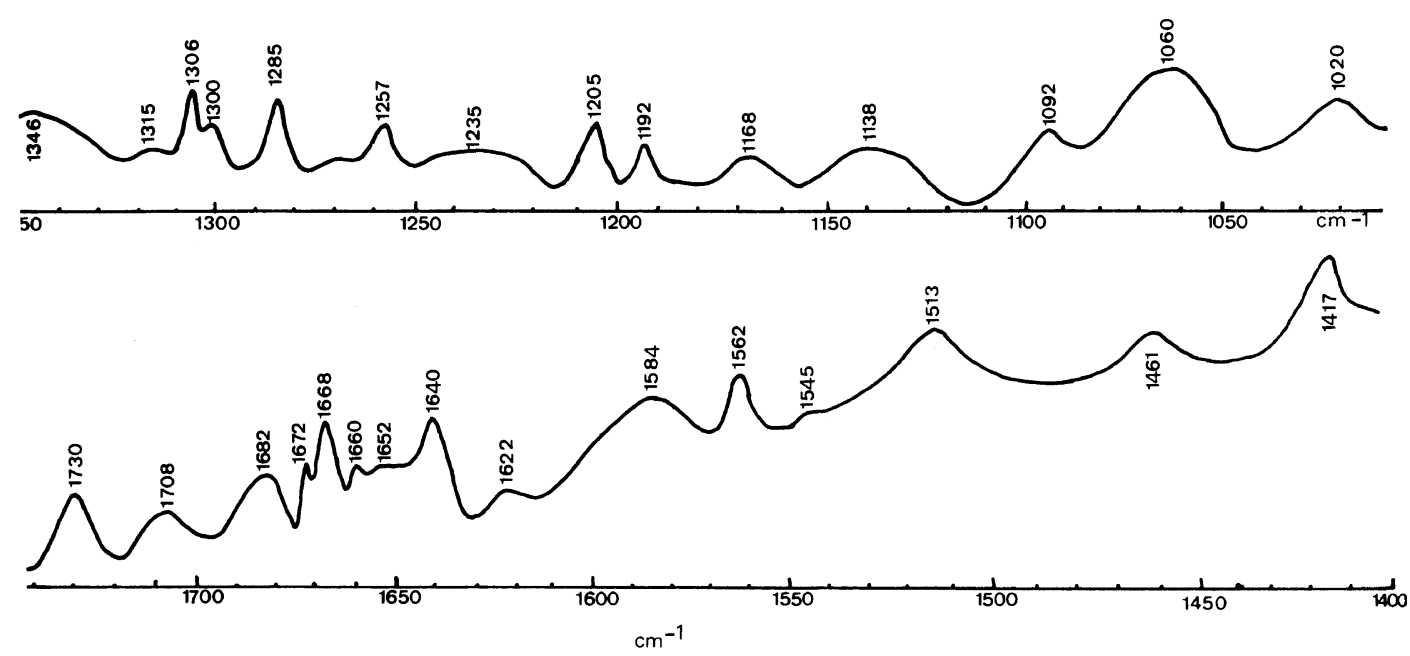

Figure 2. Raman spectra of (L-Asp $\mathrm{Na})_{n}$ in the solid state. 


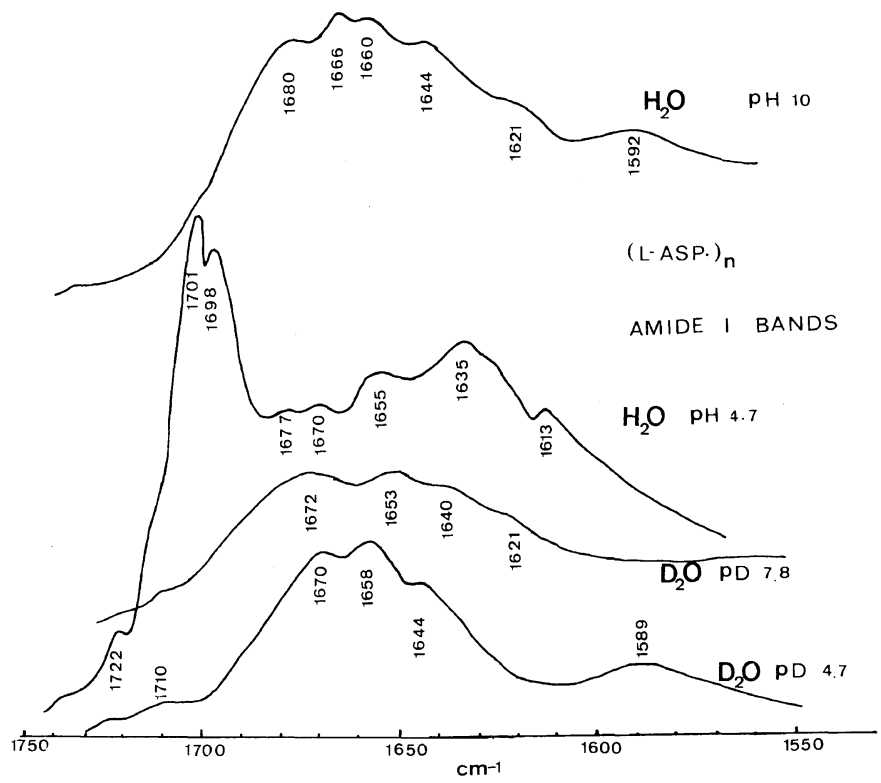

Figure 3. Raman spectra of (L-Asp) ${ }_{n}$ amide $\mathrm{I}$ bands in both $\mathrm{H}_{2} \mathrm{O}$ and $\mathrm{D}_{2} \mathrm{O}$.

of non-hydrated $\mathrm{C}=\mathrm{O}$ groups. A point of discussion is the presence in the spectra of (L-Asp Na) ${ }_{n}$ of many bands between 1755 and $1708 \mathrm{~cm}^{-1}$ corresponding to the $\mathrm{C}=\mathrm{O}$ stretching. These bands do not originate in the presence of oligomers, the samples being dialyzed and lyophilized several times before recording the spectra. The strong band at $1584 \mathrm{~cm}^{-1}$ was assigned to the ionized carboxylic groups.

The amide III band was intense like for (L-Asp) but shifted somewhat at $1235 \mathrm{~cm}^{-1}$ for the $\beta$ antiparallel pleated sheets. Another sharp band appears at $1285 \mathrm{~cm}^{-1}$. (This band is weak at $1279 \mathrm{~cm}^{-1}$ in the acidic (L-Asp) ${ }_{n}$ form.) This band can be related to the one at $1283 \mathrm{~cm}^{-1}$ for the (Gly) ${ }_{n}$ II $3_{1}$ helix structure found by Small, Fanconi, Peticolas in the solid state. ${ }^{13}$ It is unusual to find a band which seems to be in the ionized form $\left(1279 \mathrm{~cm}^{-1}\right)$ in the spectrum of

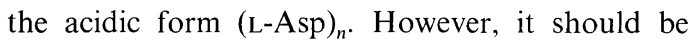
pointed out that all the carboxylic functions were not in the neutral carboxylic form in these experiments. If the $\mathrm{pH}$ is further lowered, the precipitation takes place before completion of the neutralization.

\section{Aqueous Solutions}

Only basic solutions can be prepared directly. Their concentration must be near $10 \%$ in weight.for the purpose of Raman spectrometry. Acidic solutions can be prepared by neutralization of basic ones. The spectra recorded from aqueous solutions
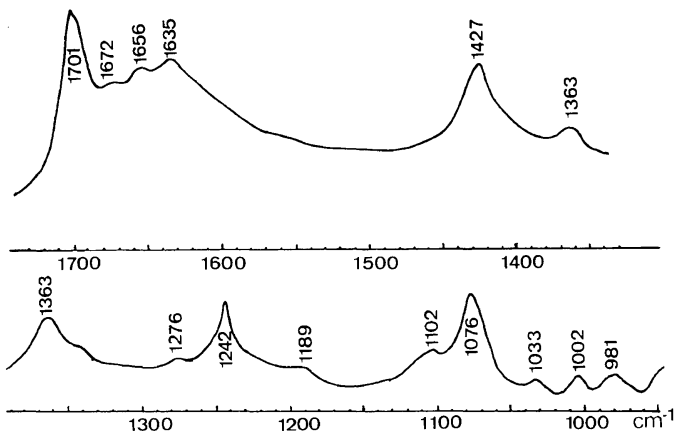

(a)

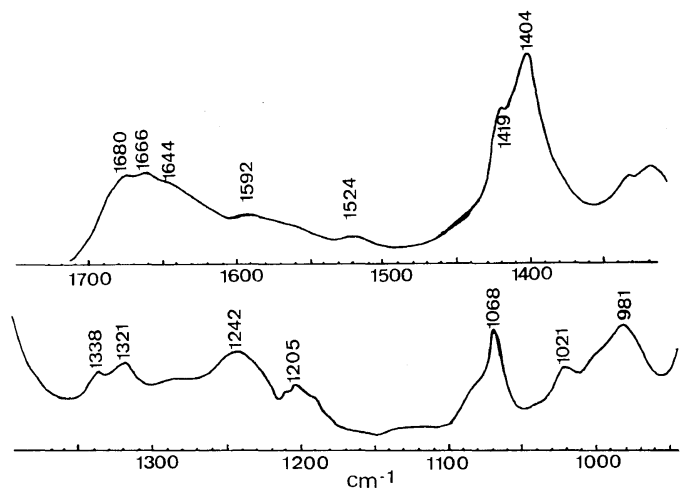

(b)

Figure 4. Raman spectra of (L-Asp): a, in $\mathrm{H}_{2} \mathrm{O}$ at $\mathrm{pH}$ 4.7 ( $10 \%$ in weight $)$; $\mathrm{b}$, in $\mathrm{H}_{2} \mathrm{O}$ at $\mathrm{pH} 10$ ( $10 \%$ in weight $)$. 
were not very different from those obtained in the solid state (Figures 1 and 4).

Whatever the $\mathrm{pH}$ of the solution is, the amide I bands are obscured by water $\left(1644 \mathrm{~cm}^{-1}\right)$. The two bands corresponding to the $\beta$ antiparallel pleated sheets appeared at 1680 and $1666 \mathrm{~cm}^{-1}$ for basic solutions (Figure $4 \mathrm{~b}$ ), and shifted to 1677 and $1670 \mathrm{~cm}^{-1}$ when the $\mathrm{pH}$ was lowered (Figure $4 \mathrm{a}$ ). A comparison can be made with the $\beta$ structures of $(\mathrm{Gly})_{n} \mathrm{I}^{13}$ and $(\mathrm{L}-\mathrm{Val})_{n}$ in the $\beta$-form ${ }^{15}$ which exhibit bands at $1674-1665 \mathrm{~cm}^{-1}$ and $1666 \mathrm{~cm}^{-1}$, respectively. The random coil conformation, observed at $1660 \mathrm{~cm}^{-1}$ in basic solutions does not disappear in acidic conditions but is shifted at $1655 \mathrm{~cm}^{-1}$ with a lower intensity. This random coil is obtained at $1656 \mathrm{~cm}^{-1}$ for (L-Glu Na) ${ }_{n}^{6}$ and at $1654 \mathrm{~cm}^{-1}$ for feather keratin. ${ }^{11}$

By lowering the $\mathrm{pH}$, a strong highly polarized band at $1635 \mathrm{~cm}^{-1}$ appeared and was assigned to the $\alpha$ helical conformation

The amide III band does not shift on lowering the $\mathrm{pH}$ of the solutions, but at basic $\mathrm{pH}$, this band is very broad at $1242 \mathrm{~cm}^{-1}$ and was assigned to the $\beta$ antiparallel conformation ${ }^{9}$ (in good agreement with the observation of Painter and Koenig ${ }^{12}\left(1239 \mathrm{~cm}^{-1}\right.$ for (L-Lys) $\left.)_{n}\right)^{7}$

The constant intensity of this band conforms that the structure does not disappear when the polyacid is dissolved in its ionized form and then neutralized.

Finally the strong band observed at $1285 \mathrm{~cm}^{-1}$ for solid (L-Asp Na) ${ }_{n}$ (Figure 3) appears in solution at $1276 \mathrm{~cm}^{-1}$ (very weak) and does not shift on lowering the $\mathrm{pH}$.

In basic solutions, a strong band at $981 \mathrm{~cm}^{-1}$ corresponds to the stretching of $\mathrm{C}-\mathrm{C}-\mathrm{N}$ bonds of the backbone. This band decreases in intensity in acidic solutions. In the same way, a strong band at $935 \mathrm{~cm}^{-1}$ in basic solutions decreases and a band at $941 \mathrm{~cm}^{-1}$ (highly polarized) increases when lowering the $\mathrm{pH}$.

It is difficult to give an assignment to these bands. However for (L-Lys) ${ }_{n}, \mathrm{Yu}^{7}$ found a band at $945 \mathrm{~cm}^{-1}$ for the $\alpha$ helix and another at about $1002 \mathrm{~cm}^{-1}$ for the $\beta$ structure $(\mathrm{C}-\mathrm{C}-\mathrm{N})_{\mathrm{s}}$ skeletal motion. We assigned the band at $941 \mathrm{~cm}^{-1}$ to the $\alpha$ helix (in acidic $\mathrm{pH}$ ) and the band at $981 \mathrm{~cm}^{-1}$ for the random coil (for both basic and acidic $\mathrm{pH}$ ).

\section{$\mathrm{D}_{2} \mathrm{O}$ Solutions}

In $\mathrm{D}_{2} \mathrm{O}$, the apparent $\mathrm{pH}$ values of the solutions

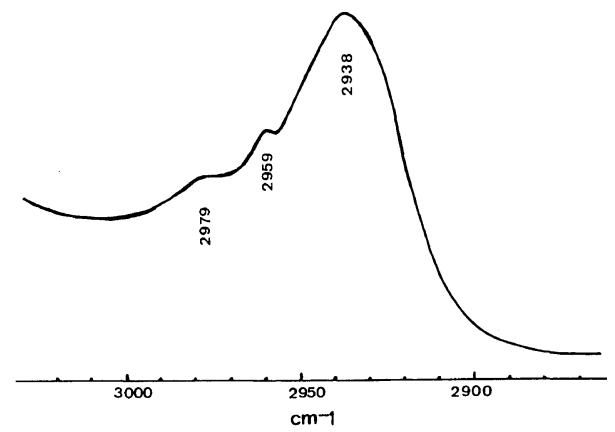

Figure 5. Raman spectra of (L-Asp Na) in $\mathrm{D}_{2} \mathrm{O}$ at pD 7.8 in the region of $\mathrm{CH}_{\alpha}$ stretching.

have been corrected by adding a value of 0.4 so $\mathrm{pD}=\mathrm{pH}+0.4$.

In $\mathrm{D}_{2} \mathrm{O}$, under the ionized form at $\mathrm{pD} 7.8$, three bands were recorded at 2979, 2938 (shoulder) and $2959 \mathrm{~cm}^{-1}$ (weak) (Figure 5). The first two can be assigned to a $3_{1}$ helical conformation at 2980 and $2940 \mathrm{~cm}^{-1}$ according to Small, et al. ${ }^{13}$ The third one is compatible with a $\beta$ conformation as for $(\mathrm{Gly})_{n} \mathrm{I}^{13}$ For basic solutions at pD 11,4 (Figure 6) and pD 7.8 (Figures 1 and $7 \mathrm{~b}$ ) three amide $\mathrm{I}^{\prime}$ bands appear at 1672,1653 , and $1638-1640 \mathrm{~cm}^{-1}$. The strong band at $1640 \mathrm{~cm}^{-1}$ may be related to the $3_{1}$ helical $N$ deuterated type (Gly) ${ }_{n}$ II conformation. ${ }^{13}$ The band at $1653 \mathrm{~cm}^{-1}$ seems to correspond to the random coil conformation; however, the corresponding random coil conformation of (L-Lys, $\mathrm{HCl})_{n}$ is found at $1660 \mathrm{~cm}^{-1} .^{7}$ If the band at $1670 \mathrm{~cm}^{-1}$ is to be comparable with the amide I of the $\beta$ antiparallel conformation, it will have to shift towards a lower frequency upon $N$-deuteration and this will be discussed below.

For "Acidic Solutions" (Figure 7 a) at pD 4.7, only a very weak band is seen at $1702 \mathrm{~cm}^{-1}$ (COOD), being just at the transition point. Below this $\mathrm{pD}$, the polypeptide precipitates. The band at $1644 \mathrm{~cm}^{-1}$ might be assigned able to the $\alpha$ helical conformation (Amide $\mathrm{I}^{\prime}$ ). The band at $1653 \mathrm{~cm}^{-1}$ at basic $\mathrm{pD}$ shifted to $1658-1660 \mathrm{~cm}^{-1}$ by lowering the $\mathrm{pD}$ and it may be concluded that some random coil conformation persists in acidic solutions to some extent. At this frequency, it was surprising to find a band at $1672 \mathrm{~cm}^{-1}$. It corresponds to the $\beta$ antiparallel conformation and should shift at $1658 \mathrm{~cm}^{-1}$ through $N$-deuteration. This observation can be correlated with the fact that a very compact $\beta_{2}$ antiparallel conformation is possible. Such a conformation has 

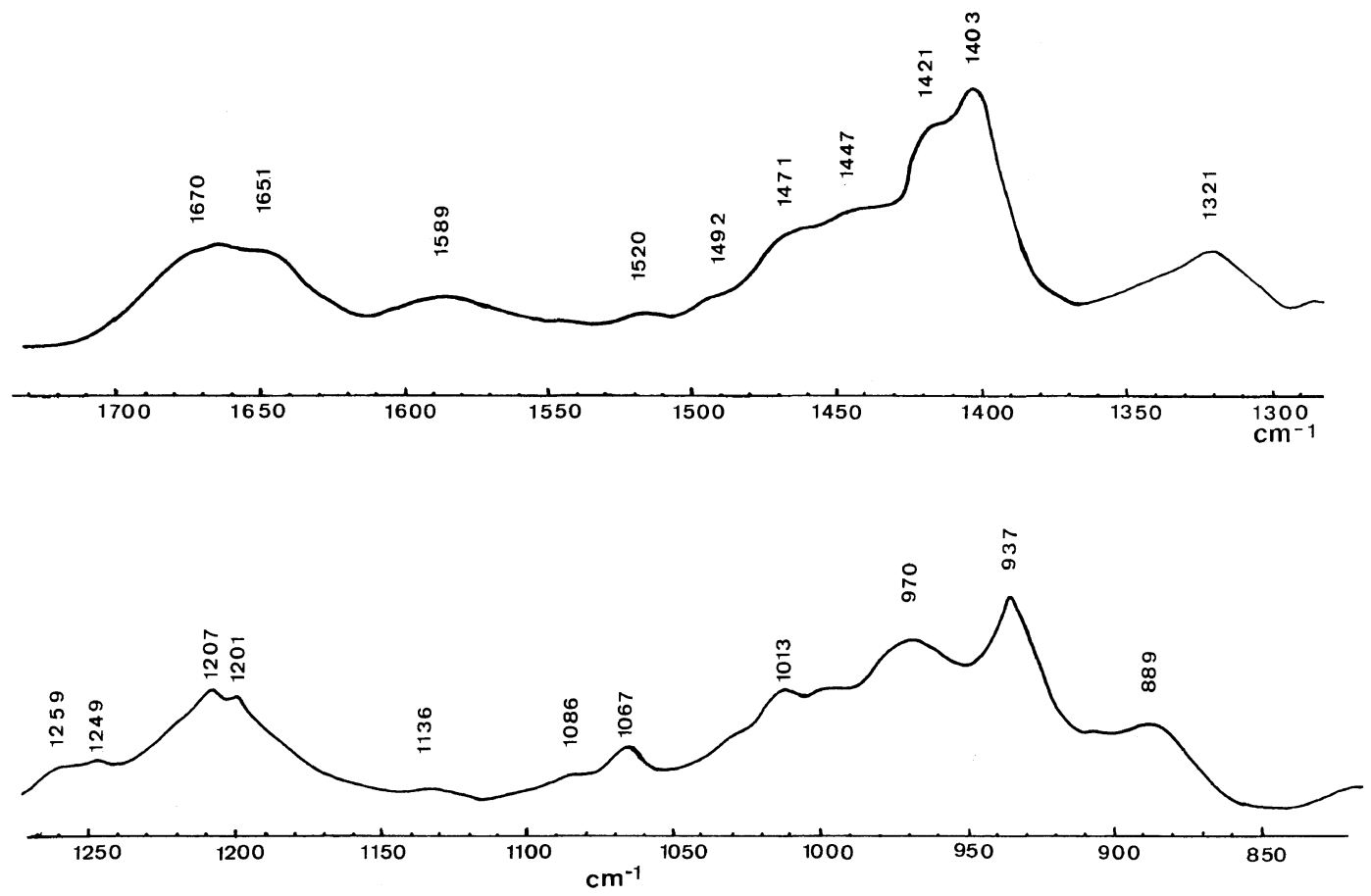

Figure 6. Raman spectra of (L-Asp $\mathrm{Na})_{n}$ in $\mathrm{D}_{2} \mathrm{O}$ in highly basic medium pD $11.4(20 \%$ in weight).

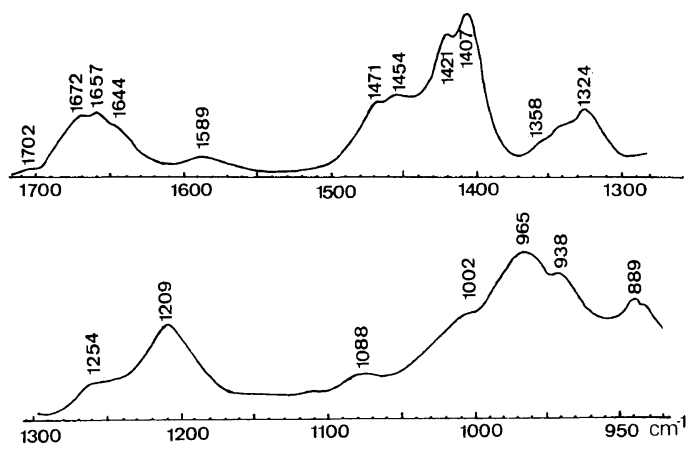

(a)

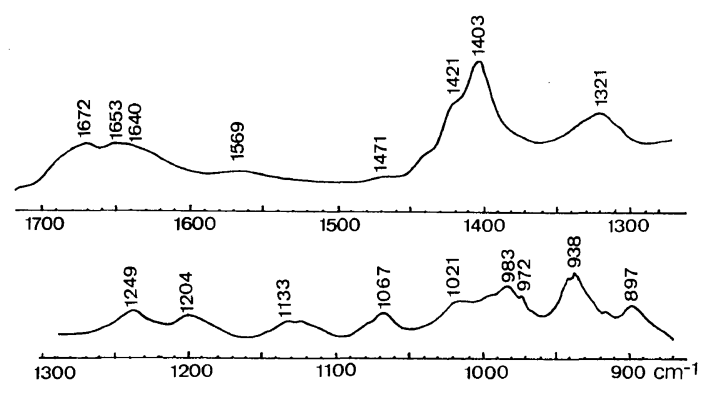

(b)

Figure 7. Raman spectra of (L-Asp) $n_{n}$ a, in $\mathrm{D}_{2} \mathrm{O}$ at pD $4.7(20 \%$ in weight $)$; b, in $\mathrm{D}_{2} \mathrm{O}$ at pD $7.8(20 \%$ in weight $)$.

been found for (L-Glu) $)_{n}$, in the acidic form, in $\mathrm{D}_{2} \mathrm{O}$ solutions. ${ }^{8}$ In the case of (L-Asp) ${ }_{n}$, the measurement of near the IR spectrum in basic solutions show that no molecules of the solvent are bound to (L-Asp) in the $\beta$ structure $^{5}$ which appears similar to the $\beta_{2}$ structure of (L-Glu) ${ }_{n} \cdot{ }^{5-8}$

Our X-ray studies ${ }^{5}$ showed that the parameters given for Itoh, et al., ${ }^{8}$ for the $\beta_{2}$ form of the antiparallel $\beta$ pleated-sheet structure of $(\mathrm{L}-\mathrm{Glu})_{n}$ in acidic form could explain a part of the rays obtained for (L-AspNa) ${ }_{n}$. (Monoclinic cell, $a=9.75 \AA$, axis of the hydrogen bonds, $b=6.84 \AA$ axis of the $\beta$ chain, and $c=8.16 \AA \pm 0.1 \AA$ for $(\mathrm{L}-\mathrm{AspNa})_{n}$ and $c=8.06 \AA$ for ( $\mathrm{L}-\mathrm{Glu})_{n}$ is the intersheets distance and $\beta=104^{\circ}$ angle between the $a$ and $c$ axis.) The $d_{\mathrm{oo} /}$ rays were the most intense for (L-AspNa) ${ }_{n}$ and changes in the value of $c$ or $\beta$ did not agree with the obtained results, despite the fact that an additive $-\mathrm{CH}_{2}$ occurs in the side-chain of $(\mathrm{L}-\mathrm{Glu})_{n}$.

The amide III' $^{\prime}$ bands are very weak. A band at 
$1013 \mathrm{~cm}^{-1}$ (medium) is recorded for very basic solutions and a weak band at $1010 \mathrm{~cm}^{-1}$ appears at pD 4.7 .

In the region of $1470-1400 \mathrm{~cm}^{-1}$, bands appear at 1471-1454-1421 and $1407 \mathrm{~cm}^{-1}$ at acidic $\mathrm{pD}$ and $1471-1421$ and $1403 \mathrm{~cm}^{-1}$ at $\mathrm{pD} 7.8$.

The bands at 1403 and $1407 \mathrm{~cm}^{-1}$ might be due to the symmetric stretching of $\left(\mathrm{COO}^{-}\right)_{\mathrm{s}}$ (residual at $\mathrm{pD}$ 4.7). The band at $1421 \mathrm{~cm}^{-1}$ keeps its intensity constant for both acidic and basic $\mathrm{pD}$ and can be assigned to the $\mathrm{CH}_{2}$ bending vibration of the methylene of the side chain.

Band around $1471^{-1}$ may be assigned to the amide $\mathrm{II}^{\prime}$ bands. This is in close agreement with the recent investigations of $\mathrm{Harada}^{14}$ who studied the preresonance Raman effect of (L-Lys) ${ }_{n}$ and (L-Glu) and found that the amide $\mathrm{II}^{\prime}$ band was strongly enhanced in the UV excited spectrum. The band corresponds to one of the shoulders on the higher frequency side of the $\left(v \mathrm{CO}_{2}^{-}\right)_{\mathrm{s}}$ streching band around $1410 \mathrm{~cm}^{-1}$ in the ordinary Raman spectra (ref 14). This band is very weak in basic solution but very intense when the $\mathrm{pD}$ is lowered to 4.7 .

Some bands at 938 and $983 \mathrm{~cm}^{-1}$ in basic solution correspond to the $\mathrm{C}-\mathrm{C}-\mathrm{N}$ skeletal stretching vibrations of $\beta$ antiparallel sheets and random coils respectively. In acidic $\mathrm{pD}$, a strong band appears at $965 \mathrm{~cm}^{-1}$ and was assigned to the $(\mathrm{C}-\mathrm{C}-\mathrm{N})$ skeletal motion of the $\alpha$ helix conformation.

\section{CONCLUSION}

Good Raman spectroscopy arguments allow for the following conclusions.

(1) In the same ionization state, relative amounts of different conformations of polyaspartic acid do not change when going from the solid state to solutions.

(2) In the ionized state, the random coil, compact $\beta$ antiparallel and $3_{1}$ helical (Gly) ${ }_{n}$ II type conformations are found.

(3) In the neutral state, the random coil, $\beta$ anti- parallel, and $\alpha$ helical conformations are found.

These results explain that only a small amount of the helical contents of (L-Asp) ${ }_{n}$ has ever been found by previous authors.

Acknowledgment. This work has been made possible with the financial support of the "Institut Regional de la Sante et de la Recherche Medicale" (I.N.S.E.R.M.) through grants I.N.S.E.R.M. ATP 17-7540 and CL 75-5-067-3. The authors are greatly indebted Dr. I. Harada for communicating his results concerning preresonance Raman spectra of (L-Glu $)_{n}$ in ionized form prior to publication and suggesting an assignment for the amide $\mathrm{II}^{\prime}$ band.

\section{REFERENCES}

1. A. Berger and E. Katchalski, J. Am. Chem. Soc., 73, 4084 (1951).

2. A. L. Jacobson, Biopolymers, 3, 249 (1965).

3. J. Brahms and G. Spach, Nature, 200, 72 (1963).

4. E. Patrone, C. Conio, A. Tealdi, and S. Brighetti, Scienze chimiche. La Ricerca Scientifica, 38 ( $\left.\mathrm{n}^{\circ} 12\right)$, 1205 (1968).

5. P. Lagant and C. Loucheux, to be published.

6. J. L. Koenig and B. Frushour, Biopolymers, 11, 1871 (1972).

7. T. J. Yu, J. L. Lippert, and W. L. Peticolas, Biopolymers, 12, 2161 (1973).

8. K. Itoh, B. M. Foxman, and G. D. Fasman, Biopolymers, 15, 419 (1976).

9. J. L. Lippert, D. Tyminski, and P. J. Desmeules, $J$. Am. Chem. Soc., 98, 7075 (1976).

10. B. G. Frushour and J. L. Koenig, Biopolymers, 14, 2115 (1975).

11. S. L. Hsu, W. H. Moore, and S. Krimm, Biopolymers, 15, 1513 (1976).

12. P. C. Painter and J. L. Koenig, Biopolymers, 15, 241 (1976).

13. E. W. Small, B. Fanconi, and W. L. Peticolas, J. Chem. Phys., 52, 4369 (1970).

14. I. Harada, private communication.

15. J. L. Koenig, J. Polym. Sci., Part D, 101, 59 (1972).

16. J. Kovacs, R. Ballina, and D. Balasubramanian, $J$. Am. Chem. Soc., 87, 1 (1965). 